\title{
Measuring unmet need for social care amongst older people
}

Athina Vlachantoni ${ }^{* 1}$, Richard Shaw*2, Rosalind Willis ${ }^{* 2}$, Maria Evandrou*, Jane Falkingham ${ }^{* 1}$ and Rebekah Luff*

${ }^{* 1}$ ESRC Centre for Population Change, ${ }^{* 2}$ EPSRC The Care Life Cycle

University of Southampton

\begin{abstract}
Recent spending cuts in the area of adult social care raise policy concerns about the proportion of older people whose need for social care is not being met. Such concerns are emphasised in the context of population ageing and other demographic changes. For example, the increasing proportion of the population aged 75 and over places greater pressure on formal and informal systems of care and support provision, while changes in the living arrangements of older people may affect the supply of informal care within the household. This article explores the concept of 'unmet need' for support in relation to specific Activities of Daily Living (ADLs) and Instrumental Activities of Daily Living (IADLs), using data on the receipt of support (informal, formal state or formal paid) from the General Household Survey, the English Longitudinal Study of Ageing and the British Household Panel Survey. The results show that different kinds of need tend to be supported by particular sources of care, and that there is a significant level of 'unmet need' for certain activities.
\end{abstract}




\section{Introduction}

Meeting older people's needs for social care has always been important, but never more so than at a time when the proportion of older people is increasing in the population, and the budgets of local councils delivering or paying for care, are facing cuts. Against this background, unmet need was recognised by the then Commission for Social Care Inspection as a key policy challenge, the measurement of which is crucial in assessing the effectiveness of social care provision ${ }^{1}$. Demographic change and policy reform, driven by the recent Dilnot Report on Fairer Care Funding $^{2}$, combine to place the study of unmet need at the centre of the policy agenda.

Population ageing, resulting in the increasing proportion of older people, has created both opportunities and challenges for individuals and policy-makers alike. On the one hand, we can now expect to live longer than ever before on average. Based on 2007-9 data, women in the UK could expect to live to age 82 on average, compared to men who could expect to live to age $78^{3}$. The Office for National Statistics (ONS) estimates that between 2000 and 2009, the proportion of persons aged 75 and over increased by almost 8 per cent. However, although overall life expectancy has been increasing for both men and women, the number of years that we can expect to spend with a limiting illness of disability has also been increasing. According to the ONS, in 1981 men could expect to spend 12.8 years of their life with a limiting illness or disability and women 16 years, and by 2007 , these figures had risen to almost 14 and 17 years respectively ${ }^{4}$. Such changes in life expectancy are anticipated to have an impact on the demand for care in later life, but they have also been accompanied by other demographic changes which may influence the supply or availability of care provision in later life. For example, changes in the employment patterns of adult children, with increases in the proportion of women working in mid-life and more people working beyond age 65 may mean people have to juggle paid work with unpaid caring responsibilities, whilst changes in patterns of family formation and dissolution may impact on the availability of both co-residential and other kin who are the main source of informal care provision.

At the same time, changes in the composition of the population have been accompanied by important shifts in the policy context of social care provision, which include the increase of overall spending on older people by councils, an increase in the cost of providing different services, a slight decrease in the overall level of services provided, and finally an 'intensification' or targeting of council services to fewer people ${ }^{5}$. Between 2003-4 and 2008-9, the gross expenditure of Councils with Adult Social Services Responsibilities in England on people aged 65 and over, who accounted for about 56 per cent of the total budget of such services, increased by 8.2 per cent to just over $£ 9$ billion. During the same time, gross expenditure on adults (aged 18-64) with mental health needs (who accounted for 7 per cent of the total budget) increased by 8.4 per cent, and on adults with learning disabilities (who accounted for one-quarter of the total budget) by 28 per cent ${ }^{6}$. However, although the overall spending on older persons has been increasing, the cost of providing services has been rising at a much faster rate. The NHS Information Centre estimates that the cost in $£$ - per person - per week has increased between $2004-5$ and $2008-9$ by 15.5 per cent in nursing care, 14.2 per cent in residential care and 26 per cent in home care, placing greater pressure on local councils purchasing such types of care $^{7}$. 
There has also been a drop in the overall amount of different kinds of services provided for older people, and a decreasing role of local councils in directly providing such services. For example, between 2004-5 and 2008-9, the total number of contact hours of home care per year reached a peak at 200 hours in 2007-8, and then decreased to 183 hours in 2008-9 ${ }^{6}$. At the same time, local councils have been less involved in the direct provision of services. Laing and Buisson's (2007) analysis shows that since the mid-1980s, places in local authority residential homes have been on the decrease $(37,500$ places in 2006), while since the early-1980s, the equivalent places in the private sector have been on the increase $\left(183,700\right.$ places in 2006) ${ }^{8}$. The role of local councils in directly providing accommodation for older people has also been on the decrease, with the proportion of all residents living in council-staffed homes dropping from 18 to 8 per cent between 2000-10, while the proportion of all residents living in homes in the independent sector rose from 53 to 66 per cent during this time ${ }^{6}$. A final trend which relates directly to the concept of need as a tool for allocating resources by local councils is the increasing targeting of resources on those most in need, or the 'intensification' of care provision. For example, the number of adults who received 'intense' home care, that is between 6-10 contact hours and six or more visits per week, increased from 73,300 in 2000 to 105,000 in $2008^{9}$. Figure 1 reflects this trend with the increase since the early 1990s in the proportion of households receiving 'high intensity' support and the simultaneous decrease in the proportion of households receiving 'low intensity' support.

\section{Figure 1 Percentage of households receiving low/high intensity home help/ home care, 1993 to 2008, England}

Per cent

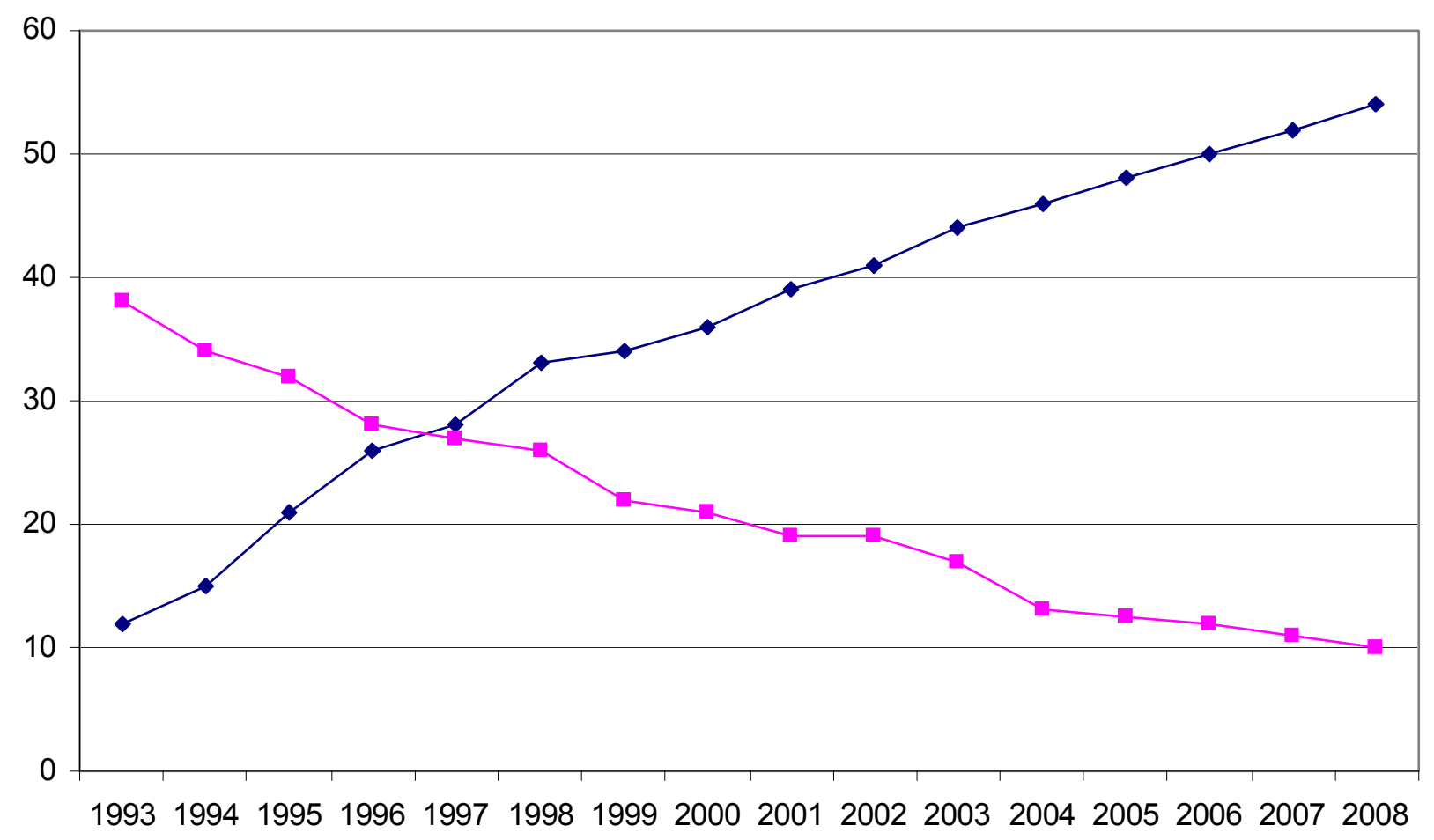

High - more than 5 hours and 6 or more visits Low - 2 hours or less and 1 visit

Source: The Health and Social Care Information Centre (2009) Community Care Statistics, Fig. 4 
Against the combination of demographic trends and changes in the policy environment, local councils have used the concept of need as a tool for targeting their resources. For example, Humphries et al note that by 2007 , approximately 72 per cent of all councils had restricted their eligibility threshold to individuals with 'substantial' or 'critical' need ${ }^{5}$. The Commission for Social Care Inspection revealed a new group of people with unmet need, with approximately one-quarter of those seeking help from local councils falling outside the councils' more stringent eligibility criteria. Of those, one-third managed without help, one-third managed with help from family members, one-quarter paid for private support and about 10 per cent were supported by a voluntary organisation ${ }^{1}$. This article builds on this background in order to understand the extent and nature of unmet need for social care in later life. The remainder of this article is structured in three sections. The second section draws on academic and policy literature to discuss the way in which 'need' has been used as one of the key concepts of welfare state design and provision. This section highlights the complexity of the concept of need on the one hand, and the further difficulty of determining the extent to which a need of a specific kind has been met. The third section introduces the data and methodology used for this article, drawing on three nationally representative datasets (ELSA, GHS, BHPS). The fourth section outlines the key findings of the article, followed by their discussion in relation to the policy implications.

\section{Conceptualising need and unmet need}

The concepts of 'need' and 'want' have always been at the centre of policy design and policy provision in modern welfare states, and the extent to which the needs of people are met by the delivery of benefits and services is a key indicator of the effectiveness of a welfare state. At the same time, the definition of need by policy-makers can attach validity to one person's needs as opposed to another person's, through the formal assessment and eligibility procedures for a benefit or service. As Liddiard notes (2007: 121), 'definitions of need, whether they are explicit in policies and eligibility rules, or implicit in the decisions made by welfare providers, are rationing devices: they determine who gets what' ${ }^{10}$. A useful starting point for defining need in the context of social care provision is Bradshaw's (1972) taxonomy, which distinguishes between five kinds of social need: normative, felt, expressed, comparative and technical ${ }^{11}$. Normative need is defined by experts or professionals using professional standards, while comparative need is defined by comparing the differences in people's access to resources (e.g. services). A person's or group's felt need is based on their own belief of need, which becomes an expressed need once it has been formulated as a demand. Finally, technical need occurs when existing provision is made more effective or a new kind of provision is invented, in which case a need for a new kind of solution arises (see also Kettner et al's 1990 similar approach ${ }^{12}$ ).

One of the difficulties of defining need, as identified by Diwan and Moriarty (1995) is the temporal dimension of the term, in other words the assumption that the needs, attitudes, expectations and values of care recipients will remain constant ${ }^{13}$. Godfrey and Callaghan (2000), in their study of a user-centred approach to need, noted that 'need is usually defined in terms of demand for existing services' (2000: 20), thereby constraining the scope of both the demand for services and the supply of services ${ }^{14}$. Therefore, as socio-demographic changes shape the values and expectations of different cohorts of older people, and technological advances account for a significant part of the rise in health and social care expenditure, projections of need and its fiscal implications have necessarily remained short-term. 
The measurement of need is at the centre of how local councils operate in terms of allocating their resources to service provision. Within England, social care for older people is provided by local councils, either directly through the placement of older people in council-owned residential homes or the provision of home care services at the recipient's home, or indirectly, through the payment by councils of such placements in private sector residential homes. As a result, the definition of what constitutes 'need' is inextricably linked with the eligibility threshold for the receipt of social care and the fiscal implications of that threshold. Local authorities use different ways in order to determine eligibility. For example, the Hampshire County Council uses up to six different sets of items relating to care management, occupational therapy, self-directed support, sensory ability, mental health and wellbeing, in order to distinguish between low, intermediate, substantial and critical levels of need as well as the type of support provided.

One part of the research to-date on need has emphasised the particular characteristics of older people receiving help from informal, state or private sources, for example people who received state help were more likely to report difficulties with Activities of Daily Living (ADLs) ${ }^{15}$. Another part of research in this area has drawn a link between the assessment of need and the eligibility criteria for the receipt of social care by local councils, often discussing the implications for the supply of and demand for social care, and what these mean in fiscal terms. For example, Cordingley, Hughes and Challis (2001) stressed the impact of variation in assessment and eligibility between local authorities and emphasised the importance of older people's perspectives in ensuring the effective targeting of social care provision ${ }^{16}$. In addition, this research highlighted a number of social groups at risk of having unmet needs, who may go unnoticed in research and policy discussions. Such groups include those with a short-term illness which may have long-term consequences, older people who provide care but require care themselves, older women living alone, older people in residential care homes and people who may have need but either choose not to seek help, or choose not to accept help which is offered.

Forder and Fernandez (2010) used the Personal Social Services Research Unit (PSSRU) dynamic micro-simulation model, which makes projections about the social care system for the future, to estimate the effects of a reduction in funding for social care provision ${ }^{17}$. The researchers used a 'demand-led' scenario of funding, where funding increases sufficiently to maintain current eligibility thresholds and means-test criteria, and a 'reduced-budget' scenario, reflecting a 6.7 per cent per annum real terms reduction in the total budget available for social care for 2011-12 and 2012-13, based on IFS calculations. The results showed that by 2012/13 there would be 9,000 'highdependency' people with unmet need under the former scenario, and 260,000 people under the latter scenario. One of the interesting issues highlighted by this research is the crucial impact of informal care provision, recognised elsewhere in the literature ${ }^{18}$. Forder and Fernandez noted that, if informal care provision was taken into consideration, by 2012/13 the level of unmet need would translate to 62 million hours of care per annum under the 'demand-led' scenario or 118 millions of hours under the 'reduced-budget' scenario, while if informal care was taken out of the estimation, these numbers would rise to 143 and 231 millions of hours respectively ${ }^{17}$. As the demographic trends described earlier indicate, the future supply of informal carers cannot be assumed ${ }^{19}$.

The conceptualisation of need involves the consideration of a person's physical, mental and emotional circumstances, which may be affected by their demographic and socio-economic characteristics. Unmet need, by contrast, relates to the amount and nature of support received by a person with needs, as well as the extent to which such support is satisfactory from that person's 
perspective. Finally, the support received by a person in need may come from informal sources, such as one's family or friends; from formal statutory sources, such as the local council; or finally from formal paid sources, such as a private physiotherapist. Figure 2 provides a simplified conceptualisation of unmet need, which is determined by the interaction between a person's type and level of need and the type and level of support they receive, and affected by their demographic, socio-economic and health status characteristics. One additional dimension has been omitted from this figure, and this is the source of support received (formal state, formal paid and/or informal).

Unmet need is concentrated within the red triangle, and can refer to different groups of people, for example those with a low level of need who receive no support (Group A), those with a moderate level of need who fall just below the formal assessment criteria (Group E), or those with high needs who receive formal support but who are unsatisfied by it (Group C). Using this figure, the conceptualisation of need and unmet need may be different, depending on one's perspective, as well as the type of need under consideration. For example, a local council's understanding of unmet need will depend on where the line of formal assessment is placed along the $X$ axis, while an older person's understanding of their own unmet need will depend on where the line of their satisfaction with support is placed along the $Y$ axis. Such satisfaction itself is subjective and cannot be generalised to a set of criteria for the older population as a whole. In addition, the figure may be relevant when conceptualising a concept of composite need, for example including both physical and emotional need, and when conceptualising different kinds of need separately.

\section{Figure 2 Conceptualising need and unmet need}

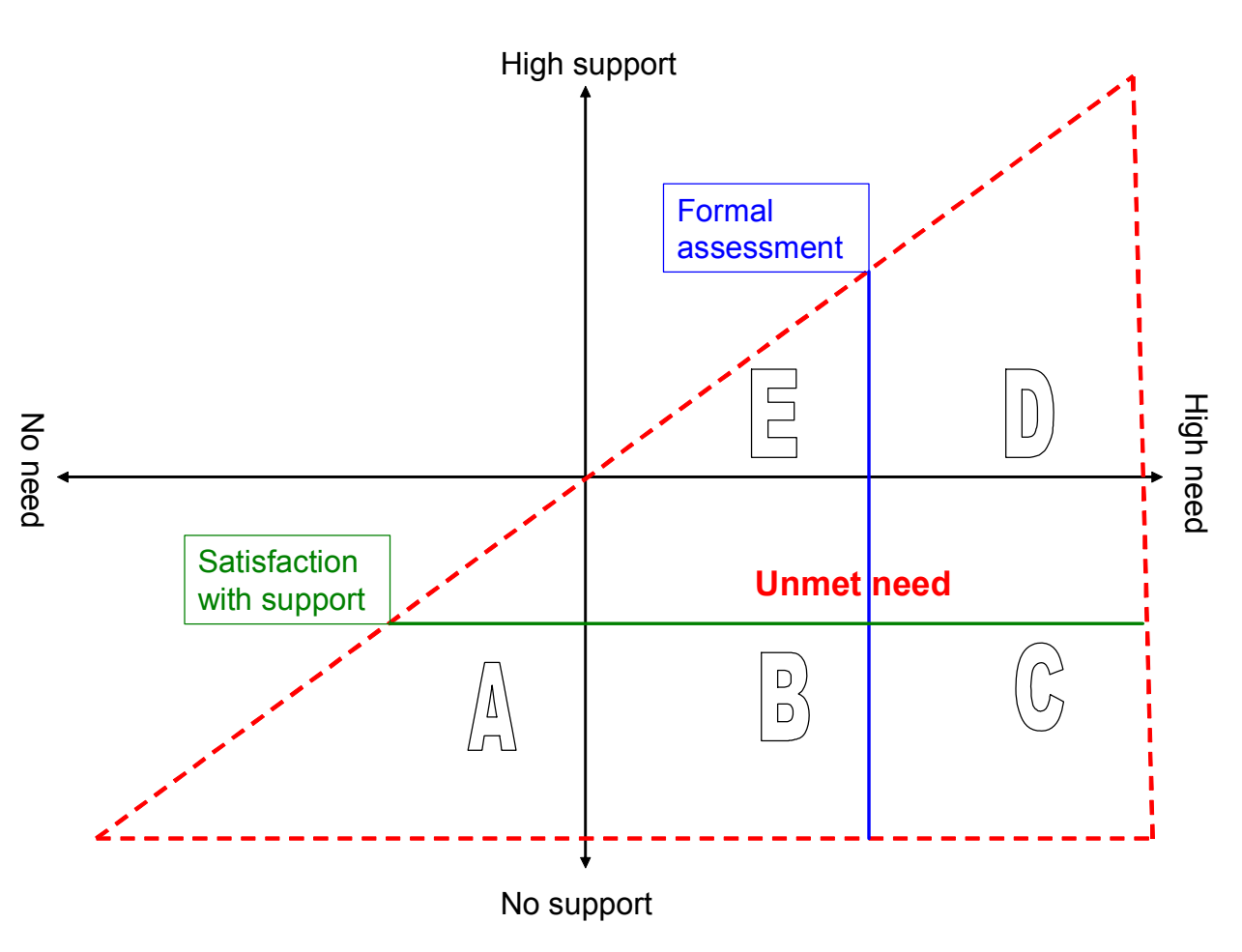




\section{Operationalising need and unmet need}

This article presents descriptive statistics using data from the General Household Survey, the English Longitudinal Study of Ageing, and the British Household Panel Survey, in order to explore the receipt of support by older people in relation to specific needs, and the extent to which there is unmet need among older people.

The General Household Survey (GHS) began in 1971 and was carried out by the ONS Social Survey Division. In 2008, the GHS became a module of the Integrated Household Survey, called the General Lifestyle Survey (GLF). When sampling for the GHS, households were selected from the Postcode Address File (PAF) and all adults (16 and over) within that household were invited to participate. In 2001-02 there were 8,889 households in the final sample, reflecting a response rate of 72 per cent. Weighting was used to account for non-response, and also to make the sample comparable with the population distribution. The topics the GHS covers include: household composition, tenure, employment, fertility, marital status, education, income, smoking, drinking, health and the use of health services. As well as the standard questions, the GHS also includes special 'modules' which differ from year to year, and in 2001-02, the modules were 'people aged 65 and over' (the 'elderly' module), 'mobility aids' and 'usual alcohol consumption in the last 12 months'. The elderly module, which was also included previously in 1980, 1985, 1991, 1994 and 1998, included questions on health, the ability to perform detailed activities of daily living (ADLs) and instrumental activities of daily living (IADLs), and whether, and from whom, help is received with these specific ADLs and IADLs. The sample size of people aged 65 and over was 3,356, and the 2001-02 GHS was the last time the elderly module was included in this survey.

The English Longitudinal Study of Ageing (ELSA) is a study of people aged 50 and over and their younger partners, living in private households in England. The sample has been drawn from households which had previously responded to the Health Survey for England (HSE) between 1998 and 2006. The HSE is an annual cross-sectional household survey which collects a wide range of health data and biometric measures. Each HSE sample is drawn using a two-stage sampling strategy, which involves a selection based on postcodes selected from the PAF and a random selection of households from a fixed number of addresses covering each postcode sector. As a result, the HSE is nationally representative of private households. There is a potential loss of representativeness before the ELSA data is drawn from HSE data due to non-response to HSE, refusal to be re-contacted, attrition between HSE and ELSA, and the exclusion of individuals living in institutions such as residential and nursing homes. These factors have been partly mitigated by weights in the ELSA. The main disadvantage of this dataset for measuring unmet need is that only respondents who reported having difficulty with at least one ADL, IADL or mobility task are asked questions about the receipt of different kinds of support, which may exclude persons who are receiving support for a different kind of need. The analysis in this article has used Wave 4 (2008) of the ELSA, which includes a total of 11,050 respondents, of whom 4,916 are aged 65 and over, and are used in the analysis ${ }^{20}$.

The British Household Panel Survey is a longitudinal survey aimed at understanding social and economic change at the individual and household level in Britain. It was designed as an annual survey of each adult member (aged 16 years and over) of a nationally representative sample of more than 5,000 households, making a total of approximately 10,000 individual interviews. The same individuals are re-interviewed in successive waves and, if they leave their original 
households, all adult members of their new households are also interviewed. Since Wave 19, the BHPS has been subsumed into a new longitudinal study called Understanding Society, or the United Kingdom Household Longitudinal Study (UKHLS), conducted by the Institute for Social and Economic Research (ISER). This article uses data collected in Wave 18 (2008-9) through the Individual Questionnaire on 15,562 individuals aged 16 and over, of whom 3,760 were aged 65 and over and were the focus of the analysis. In relation to this article, the BHPS dataset has two significant limitations. Firstly, this questionnaire does not include information on the receipt of informal support, which is the predominant source of support in later life. However, as unmet need can take different forms, this dataset is still useful in understanding unmet need for formal (state or paid) support. The second limitation of this dataset is that the report of receipt of different kinds of support is not asked in relation to specific kinds of needs: for example we know that a person who needed help in order to bath/shower was receiving formal state support; however it is difficult to understand whether such support was used by the person specifically towards bathing/ showering or whether it was used for assistance with gardening, for example.

The order and wording of questionnaire questions, as well as the filters in place throughout the questionnaire, can pose significant challenges when trying to understand the level of need and unmet need in the older population. This is illustrated by Figure 3 which shows how questions regarding need and the receipt of support have been asked in the elderly module of the General Household Survey 2001-2, and how we can deduct that part of the population who have unmet need. For example, only those who report that they find it 'fairly difficult' or 'very difficult' to perform a task on their own are subsequently asked to report whether anyone helps them with the task, and this provides us with no information about the person who finds it 'fairly easy' to perform the task on their own, and yet they may also receive help from someone inside/ outside the household.

The analysis uses the key concepts of difficulty in performing selected ADL and IADL for understanding a person's need for social care. The tool of ADL is used in order to evaluate an individual's ability to perform functional activities independently ${ }^{21}$. ADLs refer to basic functional abilities, whereas IADLs are located at a higher level of functioning, require both mental and physical capacity, and can diminish earlier than ADLs ${ }^{22}$. Finally, a person is defined as having 'unmet need' when they have a need as defined above, but do not receive help with specific tasks from any source, either formal (state or paid) or informal. In the GHS and BHPS datasets, a person is defined as having a 'need' when they either (i) are unable to perform a specific task, such as bathing, or (ii) can perform such tasks only with help, or (iii) can perform such tasks on their own but experience some degree of difficulty in doing so. In the ELSA dataset, a person is defined as being in need in the same manner as above; however only if they have reported difficulty with at least one mobility task, ADL or IADL.

\section{Results}

The results are presented in two parts: firstly, the article shows the proportion of older people with a need for care, receipt of support from different sources and unmet need (i.e. no support received) for ADLs, such as dressing and bathing/ showering. The second part of this section shows the equivalent results in relation to IADLs, such as housework/garden work and shopping. 
Figure 3 Questions on need and receipt of support in the General

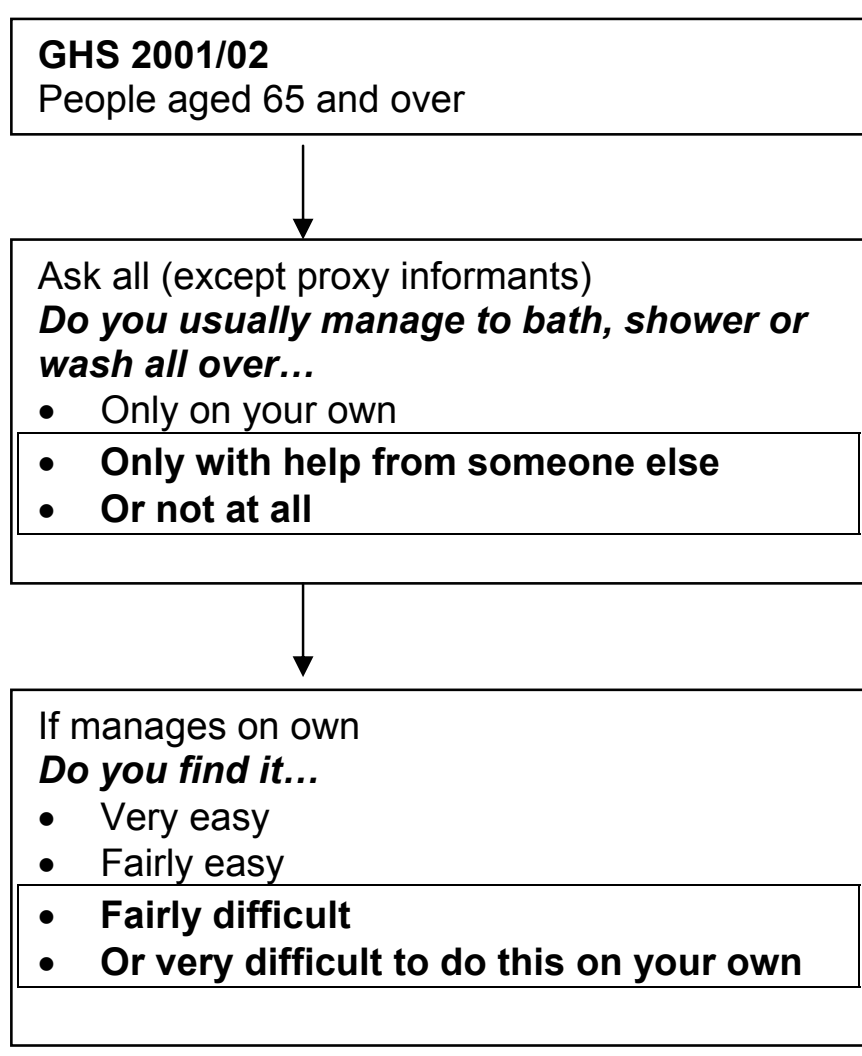

\section{Household Survey}

If they have a need and do not report receiving help from any source, then they have an UNMET NEED for bathing

Do you usually manage to bath, shower or

bathing

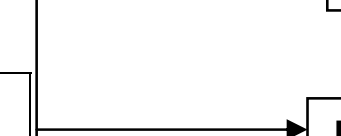




\section{Need and unmet need for Activities of Daily Living}

Table 1 uses the ELSA data to explore need and unmet need for ADLs such as dressing and bathing, and the combination of these. It shows that approximately one-tenth of the total older population reported difficulties with dressing, 6.5 per cent reported difficulties with bathing, and 9 per cent reported difficulties with both tasks. Among those who received support with such tasks, the greatest proportion received it from informal sources and formal state sources, and to a lesser extent from the private sector. For example, 27 per cent of those who reported difficulties with bathing, received informal support, 7 per cent received formal state support and 2 per cent received formal paid support. The ELSA data reflect a significant level of unmet need, that is, people who report having difficulties with bathing and/or dressing, and not receiving any kind of support. For example, two-thirds of people reporting difficulties with dressing, and 61 per cent of people reporting difficulties with bathing, did not receive any kind of support. An important caveat of these results relates to the filter used in the ELSA questionnaire, which only enquires about the receipt of different kinds of support if a person reports difficulty with at least one mobility, ADL or IADL task.

\section{Table $1 \quad$ Unmet need for Activities of Daily Living - ELSA Data (\%)}

\begin{tabular}{|c|c|c|c|}
\hline & $\begin{array}{l}\text { Reports } \\
\text { difficulties } \\
\text { with } \\
\text { dressing } \\
\text { only }\end{array}$ & $\begin{array}{l}\text { Reports } \\
\text { difficulties } \\
\text { with } \\
\text { bathing } \\
\text { only }\end{array}$ & $\begin{array}{l}\text { Reports } \\
\text { difficulties } \\
\text { with } \\
\text { dressing } \\
\text { AND bathing }\end{array}$ \\
\hline $\begin{array}{l}\% \text { within total } \\
65+\text { population }\end{array}$ & $\begin{array}{l}9.7 \\
(454)\end{array}$ & $\begin{array}{l}6.5 \\
(286)\end{array}$ & $\begin{array}{l}9 \\
(402)\end{array}$ \\
\hline
\end{tabular}

\section{Of those reporting}

\section{difficulties:}

\begin{tabular}{lccc}
$\begin{array}{l}\text { Receives informal } \\
\text { support }\end{array}$ & 31.7 & 27.4 & 50.5 \\
$\begin{array}{l}\text { Receives formal } \\
\text { state support }\end{array}$ & 1.6 & 7.3 & 19.8 \\
$\begin{array}{l}\text { Receives formal } \\
\text { paid support }\end{array}$ & $(3)$ & 2.2 & 3.3 \\
$\begin{array}{l}\text { Receives any } \\
\text { support }\end{array}$ & 34 & 38.6 & 68.4 \\
$\begin{array}{l}\text { Does not receive } \\
\text { any support }\end{array}$ & 66 & 61.4 & 31.6 \\
\hline
\end{tabular}

Note: Brackets include unweighted frequencies or cell counts below 5 .

Source: ELSA 2008.

The GHS dataset (see Table 2) shows significantly higher levels of need among the older population with specific ADLs, but lower levels of unmet need. For example, 15 per cent of the total older population reported needing help with bathing/ showering/ washing all over, and the proportion of older people who needed help with both bathing and dressing/getting in-out-of-bed was about 8 per cent, and similar to that reported in the ELSA ( 9 per cent). The questions in the 
GHS dataset include a number of filters which consecutively limit the number of persons who are asked whether they have particular needs. For example, only persons who report needing help with using stairs are asked whether they need help with dressing/ getting in-and-out-of-bed. As with the ELSA results, informal support, and to a lesser extent formal state support, provided the bulk of help for such needs, while the formal paid sector played a less important role. The results again showed a significant level of unmet need, with half of the older population who needed help with bathing and 61 per cent of the older population who needed help with dressing/ getting in-outof-bed, not receiving any support for these activities.

\section{Table $2 \quad$ Unmet need for Activities of Daily Living - GHS Data (\%)}

\begin{tabular}{llll} 
& $\begin{array}{l}\text { Needs } \\
\text { help } \\
\text { with } \\
\text { bathing } \\
\text { only }\end{array}$ & $\begin{array}{l}\text { Needs } \\
\text { help } \\
\text { with } \\
\text { dressing/ } \\
\text { in-out-of-bed } \\
\text { only }\end{array}$ & $\begin{array}{l}\text { Needs } \\
\text { help } \\
\text { with } \\
\text { bathing } \\
\text { AND dressing/ } \\
\text { in-out-of-bed }\end{array}$ \\
\hline $\begin{array}{l}\text { \% within total } \\
65+\text { population }\end{array}$ & $\begin{array}{l}15.3 \\
(476)\end{array}$ & $\begin{array}{l}10.8 \\
(341)\end{array}$ & $\begin{array}{l}8.2 \\
(257)\end{array}$ \\
$\begin{array}{l}\text { Of those who need help: } \\
\begin{array}{l}\text { Receives informal } \\
\text { support }\end{array}\end{array}$ & 37.5 & 29.7 & 25.7 \\
$\begin{array}{l}\text { Receives formal } \\
\text { state support }\end{array}$ & 8.2 & 6 & 6.5 \\
$\begin{array}{l}\text { Receives formal } \\
\text { paid support }\end{array}$ & 2.7 & 1.6 & $(3)$ \\
$\begin{array}{l}\text { Receives other } \\
\text { support }\end{array}$ & 1.6 & & \\
\hline $\begin{array}{l}\text { Receives any } \\
\text { support }\end{array}$ & 50 & 38.4 & $(3)$ \\
$\begin{array}{l}\text { Does not receive } \\
\text { any support }\end{array}$ & 49.9 & 61.2 & 38.9 \\
\hline
\end{tabular}

Note: Brackets include unweighted frequencies or cell counts below 5 .

Source: GHS 2001-2.

The BHPS data in Table 3 shows similar levels of need for ADLs to the GHS data, but significantly lower levels of unmet need. Just over 16 per cent of the total older population in the sample reported needing help with bathing, 7 per cent reported needing help with dressing, and finally 3.5 per cent reported needing help with both. As this dataset does not provide any information on the receipt of informal support, we can only deduce that formal state support was more important in addressing ADLs than formal paid support. For example, 62 per cent of people who needed help with dressing, received formal state support, and 22 per cent received formal paid support. What is important to remember when interpreting such results is that the information on need and the 
receipt of support is not 'matched', in other words we cannot assume in this dataset that a specific kind of support was received in order to assist a person with a specific need. The levels of unmet need are low; however it is important to remember that in this dataset our understanding of unmet need does not include the receipt of informal support. For example, 9 per cent of people who reported needing help with both bathing and dressing, did not receive formal (state or paid) support.

\section{Table $3 \quad$ Unmet need for Activities of Daily Living - BHPS Data (\%)}

\begin{tabular}{llll} 
& Needs & Needs & Needs \\
help & help & help \\
& with & with & with \\
& bathing & dressing & bathing \\
& only & only & AND dressing \\
\hline \% within total & 16.2 & 6.7 & 3.5 \\
$65+$ population & $(467)$ & $(238)$ & $(111)$
\end{tabular}

\section{Of those who need help:}

\begin{tabular}{lccc}
$\begin{array}{l}\text { Receives formal } \\
\text { state support }\end{array}$ & 55.2 & 62.3 & 69 \\
$\begin{array}{l}\text { Receives formal } \\
\text { paid support }\end{array}$ & 28.3 & 22.4 & 19 \\
$\begin{array}{l}\text { Receives both } \\
\text { state and paid } \\
\text { support }\end{array}$ & 1.3 & 2 & 2 \\
$\begin{array}{l}\text { Receives any } \\
\text { support }\end{array}$ & 84.7 & 84.7 & 88 \\
$\begin{array}{l}\text { Does not receive } \\
\text { any support }\end{array}$ & 15.3 & 12.5 & 9.2 \\
\hline
\end{tabular}

Note: Brackets include unweighted frequencies or cell counts below 5 .

Source: BHPS 2008.

\section{Need and unmet need for Instrumental Activities of Daily Living}

Unmet need for IADLs is qualitatively a different kind of need, which although impacting on a person's quality of life, can have a less adverse effect on a person's physical integrity and health status. In addition, a person's need in relation to IADLs may fall outside the eligibility criteria for the receipt of formal state support, which leaves a larger gap for the informal and formal paid sectors to fill. Using data from ELSA, Table 4 shows the level of need for two such tasks: shopping, and house/ garden work. Just under one-quarter of the total older population reported difficulties with shopping or house/ garden work, and almost 11 per cent reported difficulties with both tasks. The majority of people who reported difficulties with either one or both of these IADLs, received support from informal sources, but in addition, formal paid services also covered part of such needs. For example, just over half of the total population reporting difficulties with house/ garden work received informal support, and about 22 per cent received formal paid support. Finally, according 
to the ELSA data, the level of unmet need for such activities was lower than for ADLs, for example, with 7 per cent of all people reporting difficulties with both tasks not receiving any type of support.

\section{Table $4 \quad$ Unmet need for Instrumental Activities of Daily Living - ELSA Data (\%)}

\begin{tabular}{llll} 
& $\begin{array}{l}\text { Reports } \\
\text { difficulties } \\
\text { with } \\
\text { shopping } \\
\text { only }\end{array}$ & $\begin{array}{l}\text { Reports } \\
\text { difficulties } \\
\text { with } \\
\text { house \& } \\
\text { garden } \\
\text { only }\end{array}$ & $\begin{array}{l}\text { Reports } \\
\text { difficulties } \\
\text { with } \\
\text { shopping } \\
\text { AND house } \\
\text { \& garden }\end{array}$ \\
$\begin{array}{l}\text { \% within total } \\
\text { 65+ population }\end{array}$ & $\begin{array}{l}3.2 \\
(136)\end{array}$ & $\begin{array}{l}10.8 \\
(521)\end{array}$ & $\begin{array}{l}10.9 \\
(470)\end{array}$ \\
$\begin{array}{l}\text { Of those reporting } \\
\text { difficulties: }\end{array}$ & & 51.8 & 82.4 \\
$\begin{array}{l}\text { Receives informal } \\
\text { support }\end{array}$ & 85.2 & 3 & 6.6 \\
$\begin{array}{l}\text { Receives formal } \\
\text { state support }\end{array}$ & $(2)$ & & 11.2 \\
$\begin{array}{l}\text { Receives formal } \\
\text { paid support }\end{array}$ & $(3)$ & 22.5 & \\
\hline $\begin{array}{l}\text { Receives any } \\
\text { support }\end{array}$ & 88.5 & 75.7 & 93.1 \\
$\begin{array}{l}\text { Does not receive } \\
\text { any support }\end{array}$ & 11.5 & 24.3 & 6.9 \\
\hline
\end{tabular}

Note: Brackets include unweighted frequencies or cell counts below 5 .

Source: ELSA 2008.

Finally, we conducted analysis using the GHS and BHPS data in relation to IADLs (not shown here), and this showed very low levels of unmet need. For example, according to the GHS, 99.9 per cent of the population who needed help with shopping, received help, and this was mainly through informal sources.

\section{Discussion}

The measurement of unmet need is pivotal in understanding the extent to which social care provision can meet the needs of older people. This article has discussed the complexity of conceptualising and empirically investigating the concept of unmet need among older people, drawing on data from three nationally representative datasets (GHS, ELSA and BHPS). The results showed that the level of need among the older population is different depending on the particular activity in question, and also depending on the dataset consulted. For example, an older person may be asked whether their daily activities are limited as a result of their health status specifically, 
or not. The article also shows that the level of unmet need is significant regardless of the ADL or IADL used to indicate need. The receipt of informal care is central to the everyday life of older persons, and this is the case with either ADLs or IADLs; however formal state care appears to be more important in terms of ADLs than formal paid care.

On the one hand, the results reflect the methodological challenge of measuring unmet need, and the diversity in the questions asked by each of the three datasets in relation to need and the receipt of support from different sources. In addition, the results highlight the complexity of need at the conceptual level, and the need to consider the diversity within the concept itself, relating to the type of difficulty encountered, the level of difficulty encountered and the type of support received in relation to specific needs. In relation to the receipt of formal state care, the results highlight the importance of state support for older people generally, and in relation to ADLs in particular. These results also raise questions about the future role of statutory support in the face of significant demographic and policy changes.

In addition, this analysis has revealed the difficulty of obtaining data which can be effectively used to understand need and unmet need. For example, the GHS elderly module has not been included since 2001-02 and the GHS itself no longer exists in its original form. The BHPS did not enquire about support received from informal sources, while its descendent, Understanding Society, only includes questions on informal care provision and not informal care receipt. Finally, the ELSA contains filters which prevent us from having a full picture of the receipt of support by older people, while the use of levels of 'difficulty' rather than a disability gradient further complicates our understanding of need in the sample population. These factors can hamper the ability of researchers to answer important questions like the extent of unmet need for social care.

A further limitation of the surveys used in this article relates to the exclusion of older people who may potentially be those most in need. For example, with the exception of a small subset of the ELSA sample, only older people living in private households are included in the surveys.

Furthermore, there is a lack of data for those with dementia and other cognitive problems and also those who are most frail, at the end of life, in long-term care or in hospital. These groups tend to be under-represented in large surveys, and those with dementia in particular fall outside the scope of such studies, leading to there being more data on those providing care for those with dementia and other complex needs than those receiving it. Further analysis is required to understand the needs and unmet needs of some of the most vulnerable groups, in particular, those with dementia, complex needs, and communication difficulties.

An additional dimension of the nature and level of unmet need, not investigated in this article, relates to the user's perspective and the preferences of older people in terms of their needs being met. In terms of informal support, this issue is crucial vis-à-vis demographic changes which affect the availability of kin to provide care and support. In terms of formal state and paid support, this issue raises questions about the quality of care provided, and the extent to which care and support provision can be adjusted according to the recipient's preferences. However, the distribution reported here of help received from informal, formal state, and formal paid sources respectively may partly indicate the preferences of older people, as well as their demographic and socioeconomic characteristics. 
This article reflects the necessity for additional research in order to understand the demographic and socio-economic characteristics associated both with the level and type of care, and the extent and kind of support received. Further research could also investigate the particular characteristics associated with older people who report difficulty with particular tasks and are not receiving any kind of support in relation to such tasks. Finally, and perhaps most importantly, the analysis in this article highlights the importance of more precise data in order to effectively measure the level, and understand the nature, of unmet need for social care among older people. As local councils find themselves facing both expenditure cuts and reforms in their assessment and delivery procedures, evidence on unmet need is an essential element of the planning of their future provision.

\section{Key Findings}

- There is significant unmet need for social care among older people, regardless of the specific question asked or the specific dataset used. For example, among those who had difficulty or needed assistance with bathing/ showering, between 15-61 per cent reported not receiving any support at all

- Unmet need for Activities of Daily Living (ADLs) appeared to be higher than unmet need for Instrumental Activities of Daily Living (IADLs). For example, the ELSA dataset showed that 66 per cent of older people who had difficulty with dressing received no support, compared to 24 per cent of older people who had difficulty with housework or garden work

- Informal and formal state support was more likely to be received for ADLs. For example, the GHS dataset showed that 37 per cent of older people who needed assistance with bathing/ showering received informal support, 8 per cent received formal state support, and only 3 per cent received formal paid support with such a task

- Formal paid support was more likely to be received for IADLs. For example, the ELSA dataset showed that 22 per cent of older people who reported difficulty with shopping received formal paid support with such a task

\section{Acknowledgements}

This article is collaborative work between members of the ESRC Centre for Population Change (Grant number RES-625-28-0001) and the EPSRC-funded project The Care Life Cycle (Grant number 8400-508864101), both based at the University of Southampton. The authors would like to thank the rest of the members of The Care Life Cycle project for their useful comments on the article (Bijak, Brailsford, Bullock, Channon, Klein, Maslovskaya, Noble, Rossiter, Silverman, Viana). 


\section{References}

1 Commission for Social Care Inspection (CSCI) (2008) Cutting the Cake Fairly: CSCI review of eligibility criteria for social care. London: CSCI.

2 Commission on Funding of Care and Support (2011) Fairer Care Funding. The Report of the Commission on Funding of Care and Support. July 2011.

3 Office for National Statistics (2010a) 'Life expectancy at birth and at age 65 by local areas in the United Kingdom, 2007-9'. Statistical Bulletin (19 October 2010). Newport: ONS.

4 Office for National Statistics (2010b) 'Healthy Life Expectancy', Online statistics at: www.ons.gov.uk/ons/rel/disability-and-health-measurement/health-expectancies-at-birth-andage-65-in-the-united-kingdom/2006-08/health-expectancies-at-birth-and-at-age-65-in-theunited-kingdom-2006-08.pdf (accessed July 2011).

5 Humphries, R., Forder, J. and Fernandez, J-L. (2010) Securing Good Care for More People. London: The Kings Fund.

6 The NHS Information Centre (2010) Personal Social Services Expenditure and Unit Costs, England, 2008-9. London: The NHS Information Centre.

$7 \quad$ NHS Information Centre, various years. Available at: www.ic.nhs.uk (accessed July 2011).

8 Laing and Buisson (2007) Care of elderly people: market survey 2007. London: Laing and Buisson.

9 The NHS Information Centre (2008) Community Care Statistics 2008: Home Help/ Care services for adults, England. London: The NHS Information Centre.

10 Liddiard, M. (2007) 'Social Need and Patterns of Inequality', in Baldock, J. et al (eds) Social Policy (3rd ed), Oxford: Oxford University Press, pp. 129-143.

11 Bradshaw, J. (1972) 'A taxonomy of social need', New Society No. 496 (30 Mar): 640-3.

12 Kettner, P.M., Moroney, R.M. and Martin, L.L. (1990) Designing and managing programs. An effectiveness-based approach. Thousand Oaks, CA: Sage.

13 Diwan, S. and Moriarty, D. (1995) 'A Conceptual Framework For Identifying Unmet Health Care Needs of Community Dwelling Elderly', Journal of Applied Gerontology 14: 47-63.

14 Godfrey, M. and Callaghan, G. (2000) Exploring unmet need. The challenge of a usercentred response. York: Joseph Rowntree Foundation.

15 Breeze, E. and Stafford, M. (2011) 'Receipt and giving of help and care', in Banks, J. et al (eds) Financial circumstances, health and well-being of the older population in England. The 2008 English Longitudinal Study of Ageing. London: Institute for Fiscal Studies, pp. 348-385.

16 Cordingley, L., Hughes, J. and Challis, D. (2001) Unmet need and older people. Towards a synthesis of user and provider views. York: Joseph Rowntree Foundation and PSSRU. 
17 Forder, J. and Fernandez, J-L. (2010) 'The impact of a tightening fiscal situation on social care for older people', PSSRU Discussion Paper 2723. Kent, London, Manchester: Personal Social Services Research Unit.

18 Buckner, L.J. and Yeandle, S.M. (2007) Valuing Carers: Calculating the Value of Unpaid Care. Research Report Prepared for Carers UK. London: Carers UK.

19 Pickard, L. et al (2007) 'Care by spouses, care by children: Projections of informal care for older people in England to 2031', Social Policy \& Society 6 (3): 353-366.

20 National Centre for Social Research (2010), ELSA Wave 4 Core Dataset, Phase 2 Deposit, User Guide, London: National Centre for Social Research.

21 Katz, S. et al (1963) 'The Index of ADL: A Standardized Measure of Biological and Psychosocial Function'. Studies of Illness in the Aged 185: 914-9.

22 Lawton, M.P. and Brody, E.M. (1969) 'Assessment of older people: Self-maintaining and instrumental activities of daily living.' Gerontologist 9:179-186. 